\title{
PENINGKATAN PENGETAHUAN MELALUI SOSIALISASI EMPAT PILAR KEBANGSAAN PADA PELAJAR DI SEKOLAH MENENGAH DAN KEJURUAN (STUDI PADA SMAN 2 DAN SMKN 3 KOTA BENGKULU)
}

\section{KNOWLEDGE IMPROVEMENT THROUGH SOCIALIZATION OF FOUR NATIONALITY PILLAR ON STUDENTS IN HIGH SCHOOL AND VOCATIONAL SCHOOL (STUDY IN SMAN 2 AND SMKN 3, BENGKULU CITY)}

\author{
Oleh: \\ Ika Pasca Himawati, Heni Nopianti \\ Fakultas Ilmu Sosial dan Ilmu Politik, Universitas Bengkulu \\ Email: ikapasca@unib.ac.id
}

\begin{abstract}
Indonesia has culture diversity considered as national asset. But, if culture diversity is not managed well, it will trigger gap, conflict, disunity and violence. Therefore, the attempt to reconstruct four nationality pillars is essential. The goal is to give concept of beIndonesian as integrative, comprehensive, and also become the foundation to enhance national unity. Four nationality pillars are: Pancasila as national ideology, basic law of 1945 as national constitution, Negara Kesatuan Republik Indonesia (NKRI) as the form of the country and Bhinneka Tunggal Ika as the national motto. The target of this program is students in 3 senior high schools and vocational high school in Bengkulu city. The methods in community service activities are workshops through the provision of material which begins with pre-test activities and ends with post test, FGD, and mentoring. After the activity, the knowledge of the students about the four nationality pillars has increased significantly. From the activities conducted in 2 schools, it is found that the average increase of students' knowledge about the four pillars of nationality increased up to $30.8 \%$ and 38.7\%. Each school always disseminates knowledge about the four nationality pillars through teaching in each school. The distribution of knowledge about the four nationality pillars is not only done among students, but also for the teachers. The goal is to be able to reconstruct and internalize the four nationality pillars as an effort to strengthen the soul of nationalism and minimize acts of violence that can be a potential for radicalism and national division.
\end{abstract}

Keywords: Four Nationality Pillars, Nationalism, Student

\section{PENDAHULUAN}

Fenomena tindak kekerasan yang disebabkan oleh radikalisme dan aksi terorisme dalam kurun waktu 10 tahun belakang ini memang dinilai sangat meresahkan masyarakat. Hal ini karena perilaku teror yang dilakukan sering bersamaan dengan tindak kekerasan disertai peledakkan bom. Sehingga menyebabkan banyak korban jiwa. Bila menilik dari sisi bahasa, radikalisme berasal dari bahasa latin yang berarti akar, konsepsi mengenai 
radikalisme diterjemahkan menurut Kamus Besar Bahasa Indonesia (2016) sebagai 1). paham atau aliran yang radikal dalam politik; 2). paham atau aliran yang menginginkan perubahan atau pembaharuan sosial dan politik dengan cara kekerasan atau drastis; 3). sikap ekstrem dalam aliran politik. Dengan demikian radikalisme dapat diterjemahkan sebagai bentuk isme yang berhaluan pada perubahan dan pembaharuan pada aspek sosial politik melalui cara-cara kekerasaan dan ekstrem.

Menurut Munip (2012), bahwa radikalisme dapat dibedakan menjadi dua level yakni dari level pemikiran dan level aksi atau tindakan. Di level pemikiran, radikalisme masih dirasakan sebagai gagasan yang secara substansi mendukung cara-cara kekerasan dalam mencapai tujuan. Sedangkan di level aksi atau tindakan, radikalisme bisa berada di ranah sosial-politik serta agama. Keberadaan radikalisme pun sering dikaitkan dengan aksi terorisme. Hal ini karena dasar ideologi dari aksi terorisme umumnya berasal dari ideologi yang tumbuh secara radikal hingga akhirnya menghasilkan tindak kekerasan dan keberadaannya sangat meresahkan masyarakat. Dalam aturan tata negara, sebagaimana dijelaskan dalam Undang-Undang No 9 Tahun 2013 tentang Pencegahan dan Pemberantasan Tindak Pidana Pendanaan Terorisme, telah dijelaskan bahwa tindak pidana terorisme adalah segala perbuatan yang memenuhi unsur tindak pidana sesuai dengan ketentuan dalam Undang-Undang yang mengatur pemberantasan tindak pidana terorisme.

Fenomena radikalisme dan aksi terorisme rupanya memang telah menyasar ke dalam lembaga-lembaga penting seperti lembaga pendidikan. Menurut Rokhmad (2012), bahwa pendidikan dan lembaga pendidikan memiliki berpeluang besar untuk menjadi penyebar benih radikalisme dan sekaligus penangkal (baca: deradikalisasi) Islam radikal. Menurut Munip (2012), hasil penelitian survey yang dilakukan oleh Lembaga Kajian Islam dan Perdamaian (LaKIP) Jakarta pada tahun 2010 terbilang sungguh mengejutkan, sebanyak 48,9\% siswa di Jabodetabek menyatakan persetujuannya terhadap aksi radikal dan hasil survey di atas sekaligus bisa menyadarkan para guru, khususnya guru Pendidikan Agama Islam (PAI), bahwa ada bahaya yang sedang mengancam para siswanya.

Penelitian yang dilakukan oleh Aidulsyah (2016) memperoleh kesimpulan bahwa a) ruang publik Rohis yang ada di beberapa SMAN Eks-Karesidenan Surakarta tidak bersifat netral. Hal ini disebabkan karena adanya ruang publik Rohis telah menjadi arena perebutan, dikonstruksi, dan dihegemoni oleh berbagai gerakan Islam melalui pattern yang beragam. Disamping itu, hasil penelitian tersebut menjelaskan pula bahwa tidak seluruh ideologi gerakan Islam yang hadir di ruang publik Rohis mampu selaras dengan pengembangan nilai-nilai citizenship dan demokrasi. Kondisi ini telah mengakibatkan ruang publik Rohis terperangkap dalam eksklusivitas serta kesulitannya dalam menerima perbedaan Kondisi ini semakin menjelaskan bahwa radikalisme telah meningkat, sehingga menyebabkan kadar toleransi dan pluralisme semakin merosot. Hampir dapat dipastikan bahwasanya nilai- nilai dalam 4 pilar bangsa sudah mula pudar di kalngan generasi muda berdasarkan data-data moral dan kriminalitas yang banyak dilakukan generasi muda (Angelia, 2017). Lebih lanjut, (Azca, 2011) menjelaskan bahwa praktik "Islamisasi" budaya sekolah yang secara sistematis telah dilakukan, misalnya melalui jalur-jalur ekstrakulikuler dan kegiatan sekolah lainnya, seperti adanya praktik hijab dilingkungan kegiatan ekstrakulikuler.

Melihat situasi tersebut maka kiranya ada beberapa hal yang diasumsikan melatarbelakangi kondisi tersebut. Salah satunya karena minimnya kompetensi dan standar isi serta pemahaman dari guru-guru agama mengenai tindak radikalisme dan aksi terorisme, minimnya latar belakang pendidikan agama dari para siswa itu sendiri, serta minimnya tindakan preventif yang dilakukan oleh pihak sekolah (Rokhmad, 2012). Oleh 
karenanya memang diperlukan penguatan kapasitas pemahaman secara integratif, holistik serta komprehensif mengenai konsep ke-Indonesian sebagai dasar persatuan melalui merekonstruksi kembali pemahaman mengenai Empat Pilar Kebangsaan yang menjadi pondasi yang mendukung persatuan dan kesatuan. Keempat Pilar Kebangsaan tersebut meliputi: Pancasila sebagai ideologi negara, Undang-Undang Dasar 1945 sebagai konstitusi negara, Negara Kesatuan Republik Indonesia sebagai bentuk negara serta Bhinneka Tunggal Ika sebagai semboyan negara. Konsepsi wacana ini sejatinya menjadi kontra narasi yang menjadi dasar para siswa sehingga menghasilkan cara berpikir yang terbuka ditengah kemajemukan-isme, kelompok, ideologi, golongan yang beragam dan sikap inklusif terhadap perbedaan. Sehingga mampu membangun relasi sosial di luar kelompoknya sebagai upaya mendinamisasikan wacana dan pikiran sehingga meminimalisir cara berpikir ekslusif yang menyebabkan tindak radikalisme dan aksi terorisme.

Oleh karena itu, perlu kiranya merekonstruksi kembali pemikiran tersebut di level siswa. Dipilihnya siswa karena konsep ke-Indonesiaan yang terkandung dalam Empat Pilar Kebangsaan, sangat perlu ditanamkan sejak awal, sehingga para siswa dapat belajar untuk menginternalisasikan empat pilar kebangsaan sejak usia muda. Sehingga dapat memahami keragaman budaya yang ada di Indonesia. Sehingga dapat menumbuhkan sikap nasionalisme yang merupakan suatu sikap dan pandangan dari suatu kesatuan dalam kelompok masyarakat yang ingin hidup bersama karena memiliki kesamaan tertentu dan memiliki perasaan cinta kepada tempat tinggalnya atau disebut juga bangsa (Widiatmika, 2016). Adapun tujuan dari kegiatan ini antara lain :

1. Memberikan keterbukaan wawasan mengenai isu radikalisme dan terorisme ditengah pluralitas dan kemajemukan Indonesia;

2. Memberikan pengetahuan dan penguatan kapasitas pemahaman berpikir mengenai empat pilar kebangsaan sebagai upaya mencegah tindak radikalisme dan aksi terorisme secara substantif dan komprehensif;

3. Meningkatkan kesadaran dan daya pikir kritis para pelajar yang notabennya merupakan pemuda untuk dapat mengenali beragam aliran dan pemikiran di tengah kemajemukan ideologi di Indonesia;

4. Mendistribusikan informasi kepada rekan sebaya mengenai pentingnya pemahaman Empat Pilar Kebangsaan sebagai pondasi dalam menciptakan Indonesia yang kuat dan tangguh;

5. Menuangkan ide gagasan secara tertulis guna menciptakan "Indonesia yang aman dan tertib".

\section{METODE PENGABDIAN}

Menurut Azca (2011), ada dua strategi utama yang dapat dilakukan dalam mencegah maraknya radikalisasi keagamaan di kalangan kaum muda. Pertama, melakukan kontra wacana, gagasan serta narasi, kedua menyokong dan mengembangkan terbangunnya relasi dan jejaring sosial yang majemuk. Artinya, keterbukaan mengenai wacana dan gagasan di luar paham radikalisme sebagai paham sempit menjadi hal yang mutlak untuk dilakukan. Pengembangan wacana tersebut dapat dilakukan dengan tidak hanya mengenal aliran pemikiran yang ekslusif namun juga memperluas wacana mengenai beragam aliran pemikiran yang terbuka dan inklusif. Serta dengan peningkatan pengetahuan Empat Pilar Kebangsaan yang sebenarnya telah lama diajarkan pada jenjang sekolah pertama hingga 
menengah. Penguatan kapasitas pengetahuan ini dimaksudkan sebagai upaya dalam membangun wacana serta upaya membangun relasi dan jejaring sosial majemuk. Adapun upaya pemecahan masalah dalam kegiatan ini meliputi beberapa metode antara lain adalah sebagai berikut:

a. Workshop

Kegiatan ini dilakukan melalui penyelenggaraan workshop dengan mengadopsi mekanisme ceramah sebagai upaya dalam mendistribusikan pengetahuan (transfer of knowledge) kepada para pelajar sebagai upaya mengenalkan dan meningkatkan pengetahuan, kesadaran dan pemahaman mengenai Empat Pilar Kebangsaaan. Pada aspek ini proses sosialisasi memegang peranan penting yang bertujuan agar anak dapat menyerap informasi dan nilai yang terkandung di dalam Empat Pilar Kebangsaan.

b. FGD (Focus Group Discussion)

Secara sederhana, FGD (Focus Group Discussion) dapat didefinisikan sebagai suatu diskusi yang dilakukan secara sistematis dan terarah mengenai suatu isu atau masalah tertentu. Focus Group Discussion merupakan salah satu upaya dialogis secara tearah yang memuat tanya jawab mengenai persoalan yang mengulas mengenai Empat Pilar Kebangsaaan sebagai pondasi dalam mencegah tindak radikalisme dan aksi teorisme di Indonesia. Dalam FGD ini, para peserta diberikan kesempatan seluas-luasnya untuk bertanya guna mendapatkan informasi dan pengetahuan secara mendalam.

c. Pendampingan

Pendampingan merupakan kegiatan yang dilakukan pasca pemberian informasi dan pengetahuan terkait dengan Empat Pilar Kebangsaaan sebagai pondasi dasar dalam menjaga NKRI ditengah maraknya isu radikalisme dan terorisme di Indonesia. Tujuan dari kegiatan pendampingan ini ialah mempraktekkan informasi dan pengetahuan yang telah didapatkan. Pada kegiatan ini, pendampingan yang dilakukan bersifat berkesinambungan hingga para pelajar memahami secara komprehensif materi yang disampaikan serta mampu menyebarluaskan informasi dan pengetahuan yang telah diperoleh kepada orang lain yang ada disekitar mereka.

\section{HASIL DAN PEMBAHASAN}

Kegiatan pengabdian masyarakat dengan judul Peningkatan Pengetahuan Melalui Sosialisasi Empat Pilar Kebangsaan Pada Pelajar di Sekolah Menengah dan Kejuruan di Kota Bengkulu diselenggarakan di 3 Sekolah Menengah Atas yakni: Sekolah Menengah Atas Negeri 2 Kota Bengkulu dan Sekolah Menengah Atas Kejuruan Negeri 3 Kota Bengkulu.

Kegiatan pengabdian dimulai dengan langkah koordinasi antara anggota tim dengan pihak sekolah. Selanjutnya, penyelengaraan kegiatan workhsop dilakukan melalui pemberian materi yang sebelumnya didahului dengan pre-test dan post-test untuk dijawab para peserta. Pre-test dan post-test ini merupakan bentuk instrumen berupa kuesioner sebagai sarana evaluasi kegiatan. Oleh tim, para peserta diberikan waktu untuk mengisi instrumen tersebut selama lebih kurang 10 menit. Jumlah soal dalam pre-test maupun posttest ialah sebanyak 5 pertanyaan. Setelah proses pengisian kuesioner, maka kegiatan dilanjutkan dengan workshop. Adapun substansi materi yang diberikan kepada para peserta meliputi hal berikut ini :

a. Pengenalan kondisi Indonesia secara geografis dan demografis serta keragaman budaya yang ada di Indonesia

b. Tantangan kehidupan kebangsaan indonesia (Eksternal dan Internal)

c. Potensi yang dapat merusak kehidupan berbangsa dan bernegara 
d. Akar historis radikalisme dan terorisme di Indonesia

e. Empat Pilar Kebangsaan di Indonesia yakni: Pancasila, UUD 1945, NKRI dan Bhinneka Tunggal Ika

f. Implementasi Empat Pilar Kebangsaan dalam kehidupan sehari-hari

Kegiatan Pengabdian masyarakat di SMAN 2 Kota Bengkulu diselenggarakan di Kelas XI (sebelas). Jumlah peserta yang hadir ialah 30 orang. Tim Pengabdian Masyarakat memilih kelas tersebut setelah melakukan koordinasi dengan pihak sekolah. Kegiatan diselenggarakan sekitar 2-3 jam. Awal sesi dimulai dengan pengisian pre-test yang dibagikan oleh tim pengabdian masyarakat kepada para peserta kegiatan. Mereka diminta untuk mengisi kegiatan berlangsung dengan lancar, setelah moderator dan narasumber mulai menyampaikan materi selama 45 menit dan disusul dengan sesi diskusi dan pengisian postest sebagai bentuk instrument evaluasi untuk mengukur tingkat pengetahuan dan pemahaman siswa pada materi yang telah diberikan. Berdasarkan hasil pre-test (sebelum penyampaian materi) diperoleh data sebagai berikut (Tabel $1 \& 2$ ):

Tabel 1. Data skor hasil pre-test (sebelum penyampaian materi)

\begin{tabular}{cccc}
\hline No & Perolehan Nilai & Jumlah Peserta & Total Skor \\
\hline 1. & 40 & 3 Orang & 120 \\
2. & 60 & 19 Orang & 1140 \\
3. & 80 & 3 Orang & 240 \\
4. & 100 & 5 Orang & 500 \\
\hline \multicolumn{2}{c}{ Rata-rata } & $\mathbf{6 6 , 7}$
\end{tabular}

Sedangkan hasil post-test setelah penyampaian materi adalah sebagai berikut:

Tabel 2. Data skor post-test (setelah penyampaian materi)

\begin{tabular}{cccc}
\hline No & Perolehan Nilai & Jumlah Peserta & Total Skor \\
\hline 1. & 80 & 19 Orang & 1520 \\
2. & 100 & 11 Orang & 1100 \\
\hline \multicolumn{4}{c}{ Rata-rata } \\
\hline
\end{tabular}

Dari data tersebut diperoleh gambaran bahwa rata-rata pengetahuan siswa mengenai empat pilar kebangsaan sebelum mendapakan materi dalam pengisian pre-test adalah sebesar 66,7 dan setelah mendapatkan materi serta mengisi post test naik menjadi 87,3. Kenaikan tingkat pengetahuan tersebut mencapai $30.8 \%$. Hal ini mengindikasikan bahwa pemberian materi telah meningkatkan pengetahuan siswa secara mendalam mengenai mengenai Empat Pilar Kebangsaan.

Selanjutnya, kegiatan pengabdian masyarakat diselenggarakan di SMKN 3 Kota Bengkulu. Kegiatan diselenggarakan selama 2 jam. Para peserta yang hadir merupakan perwakilan dari seluruh jurusan yang berasal dari kelas X-XII. Acara diawali dengan sambutan dari Pihak SMKN 3 Kota Bengkulu dan pengisian pre-test oleh seluruh peserta serta dilanjutkan dengan pengisian materi dari narasumber. Kegiatan berlangsung dengan lancar setelah moderator dan narasumber mulai menyampaikan materi selama 45 menit dan disusul dengan sesi diskusi dan dilanjutkan dengan acara pengisian instrumen evaluasi berbentuk post-test yang dijawab oleh para peserta setelah mendapatkan materi dari narasumber. Berdasarkan hasil pre-test (sebelum penyampaian materi) di SMKN 3 Kota Bengkulu diperoleh data sebagai berikut (Tabel 3\&4). 

Tabel 3. Penilaian hasil pre-test (sebelum penyampaian materi) di SMKN 3 Kota Bengkulu

\begin{tabular}{cccc}
\hline No & Perolehan Nilai & Jumlah Peserta & Total Skor \\
\hline 1. & 20 & 1 Orang & $\mathbf{2 0}$ \\
2. & 40 & 10 Orang & 400 \\
3. & 60 & 14 Orang & 840 \\
4. & 80 & 9 Orang & 720 \\
5. & 100 & 5 Orang & 500 \\
\hline \multicolumn{5}{r}{ Rata-rata } & $\mathbf{6 3 , 5 8}$ \\
\hline
\end{tabular}

Pada hasil post-test (setelah penyampaian materi) pada siswa di SMKN 3 Kota Bengkulu menunjukkan data sebagai berikut:

Tabel 4. Penilaian hasil post-test (setelah penyampaian materi) pada siswa di SMKN 3 Kota Bengkulu

\begin{tabular}{cccc}
\hline No & Perolehan Nilai & Jumlah Peserta & Total Skor \\
\hline 1. & 60 & 4 Orang & 240 \\
2. & 80 & 15 Orang & 1200 \\
3. & 100 & 20 Orang & 2000 \\
\hline \multicolumn{3}{r}{ Rata-rata } & $\mathbf{8 8 , 2 0}$ \\
\hline
\end{tabular}

Dari data tersebut diperoleh gambaran bahwa rata-rata pengetahuan siswa mengenai empat pilar kebangsaan sebelum mendapakan materi dalam pengisian pre-test adalah sebesar 63,58 dan setelah mendapatkan materi serta mengisi post-test naik menjadi 88,20. Kenaikan tingkat pengetahuan tersebut mencapai 38,7. Tidak jauh berbeda dengan kondisi di SMAN 2 Kota Bengkulu, bahwa materi yang diberikan telah meningkatkan pengetahuan mengenai Empat Pilar Kebangsaan kepada siswa. Pengetahuan merupakan komponen kognitif yang menjadi bagian dari perilaku (Shandi, 2014). Dengan demikian, melalui pengetahuan yang diperoleh dari proses sosialisasi tersebut maka siswa dapat memahami empat pilar kebangsaan sebagaimana yang telah disosialisasikan oleh Majelis Permusyawaratan Rakyat PRRI (2012), bahwa empat pilar seyogyanya dipandang sebagai suatu yang harus di pahami oleh para penyelenggaraan negara bersama seluruh masyarakat dan menjadi panduan dalam menjalankan kehidupan berpolitik, menjalankan pemerintahan, menegakkan hukum, mengatur perekonomian negara, interaksi sosial kemasyarakatan, dan berbagai dimensi kehidupan bernegara dan berbangsa lainnya (Angelia, 2017). Termasuk dalam hal ini adalah siswa yang merupakan generasi bangsa. Sehingga dapat menjadi dasar dan keyakinan dalam berpikir, bersikap dan berperilaku guna mewujudkan Indonesia yang adil, damai, sejahteras serta bermartabat.

\section{KESIMPULAN DAN SARAN}

\section{Kesimpulan}

Kegiatan Pengabdian Masyarakat yang berjudul "Peningkatan Pengetahuan Melalui Sosialisasi Empat pilar Kebangsaan Sebagai Upaya Preventif Tindak Radikalisme dan Aksi Terorisme Pada Pelajar di Sekolah Menengah Atas Kota Bengkulu”telah diselenggarakan di 2 sekolah, yakni: SMAN 2 dan SMKN 3 Kota Bengkulu. Berdasarkan kegiatan pengabdian masyarakat di SMAN 2 diperoleh data rata-rata pengetahuan siswa mengenai Empat Pilar Kebangsaan mengalami kenaikan mencapai $30.8 \%$ setelah mendapatkan materi yang diberikan oleh tim pengabdian masyarakat. Hal serupa juga terjadi di SMKN 3 Kota Bengkulu dimana, kenaikan pengetahuan siswa yang diukur 
melalui post-test setelah mendapatkan materi dari narasumber mencapai $38,7 \%$. Hal ini menujukkan adanya tingkat kenaikan yang cukup signifikan pada siswa mengenai Empat Pilar Kebangsaan.

\section{Saran}

Kegiatan pengabdian masyarakat yang mengenai Empat Pilar Kebangsaan ini memang menjadi salah satu upaya preventif dalam memberikan pemahaman kepada para siswa serta perlu dilakukan ke lebih banyak sekolah. Disamping itu, perlunya koordinasi dan pemahaman yang serupa dapat diberikan kepada guru-guru SMA (guru mata pelajaran Agama, PPKN, Sosiologi dan lain-lain) untuk dapat terus mendistribusikan Empat Pilar Kebangsaan sebagai upaya penguatan jiwa nasionalis para pelajar di masa mendatang serta meminimalisir tindakan kekerasan yang dapat menjadi potensi radikalisme dan perpecahan bangsa.

\section{DAFTAR PUSTAKA}

Angelia, Nina, 2017, Pemahaman Penanaman Empat Pilar Kebangsaan terhadap Siswa SMA Negeri 4 Medan, Jurnal Ilmu Pemerintahan dan Sosial Politik UMA, 5 (1) (2017): 15-20.

Aidulsyah, Fachri, 2016, Berebut Ruang Publik Sekolah Pasca Orde Baru: Studi Kasus Pertarungan Politik Ideologi di Kerohanian Islam (ROHIS) SMAN EksKaresidenan Surakarta,Gadjah Mada.Jurnal Studi Pemuda,Vol. 5,No. 1, Mei 2016, hal 370-385.

Azca, N, 2011, Pemuda Pasca Orba: Pemuda (i) dan Radikalisme Agama (Sebuah Ikhtiar Eksploratif) Yogayakarta: Youth Studies Centre FISIPOL UGM.

Kamus Besar Bahasa Indonesia yang diakses melalui kbbi.web.id pada Selasa 11 April 2017 Pukul 22.10 WIB.

Munip, A, 2012, Menangkal Radikalisme Di Sekolah, Jurnal Pendidikan Islam, 1:159-181.

Rokhmad, A, 2012, Radikalisme Islam dan Upaya Deradikalisasi Paham Radikal, Walisongo, 20(1):79-114.

Shandi, Frenilya, dkk, 2014, Hubungan Pemahaman Empat Pilar Kebangsaan Dengan Sikap Siswa Menghadapi Arus Globalisasi diakses http://download.portalgaruda. org/article.php? article $=288997 \&$ val $=7237 \&$ title $=H U B U N G A N \% 20 P E M A H A M A N$ \%20EMPAT\%20PILAR\%20KEBANGSAAN\%20DENGAN\%20SIKAP\%20SISWA\% 20MENGHADAPI\%20ARUS\%20GLOBALISASI pada Selasa, 22 September 2018 Pukul 02.10 WIB.

Undang-Undang No 9 Tahun 2013 tentang Pencegahan dan Pemberantasan Tindak Pidana http://webcache.googleusercontent.com/search?q=cache:WzCUjB8ZiQMJ: www.hukumonline.com/pusatdata/downloadfile/lt516675034ff03/parent/lt51667443 e5d3d+\&cd=1\&hl=en\&ct=clnk\&gl=id\&lr=lang_en\%7Clang_id di akses pada 20 Juli 2018.

Widiatmika, Pipit, 2016, Pembangunan Karakter Nasionalisme Peserta Didik Di Sekolah Berbasis Agama Islam, JPK: Jurnal Pancasila dan Kewarganegaraan, Vol. 1, No. 1, Juli 2016, hal 25-33. 